Article

\title{
Examining the Interdependence between the Exchange Rates of China and ASEAN Countries: A Canonical Vine Copula Approach
}

\author{
Jianxu Liu ${ }^{1,2}$, Mengjiao Wang ${ }^{2, * \mathbb{D}}$ and Songsak Sriboonchitta ${ }^{2}$ \\ 1 Faculty of Economics, Shandong University of Finance and Economics, Jinan 250000, China; \\ liujianxu1984@163.com \\ 2 Faculty of Economics, Chiang Mai University, Chiang Mai 50200, Thailand; songsakecon@gmail.com \\ * Correspondence: mengjiaow1991@163.com
}

Received: 11 September 2019; Accepted: 30 September 2019; Published: 3 October 2019

\begin{abstract}
Based on the canonical vine (C-vine) copula approach, this paper examines the interdependence between the exchange rates of the Chinese Yuan (CNY) and the currencies of major Association of Southeast Asian Nations (ASEAN) countries. The differences in the dependence structure and degree between currencies before and after the Belt and Road (B\&R) Initiative were compared in order to investigate the changing role of the Renminbi (RMB) in the ASEAN foreign exchange markets. The results indicate a positive dependence between the exchange rate returns of CNY and the currencies of ASEAN countries and show the rising power of RMB in the regional currency markets after the B\&R Initiative was launched. Besides this, the Malaysian Ringgit proved to be most relevant to the other ASEAN currencies, thus playing an important role in the stability of regional financial markets. Moreover, evidence of tail dependence was found in the returns of three currency pairs after the B\&R Initiative, which implies the presence of asymmetric dependence between exchange rates. The results from time-varying $\mathrm{C}$-vine copulas further confirmed the robustness of the results from the static C-vine copulas.
\end{abstract}

Keywords: C-vine copulas; dependence structure; the Belt and Road Initiative; RMB; ASEAN currencies; tail dependence

\section{Introduction}

Since the Belt and Road (B\&R) Initiative was proposed by China's President Xi Jinping in 2013, China has expanded its "circle of friends" in the B\&R region with fruitful achievements in economic cooperation. These deepening ties have intensified the interdependence of financial markets between China and B\&R countries, and the currency market is no exception. Furthermore, with the sustained growth of China's share in international trade and the B\&R Initiative furthering Chinese investment overseas, the process of the internationalization of the Chinese Yuan Renminbi (CNY or RMB) has been speeding up in recent years. In October 2016, the inclusion of the RMB in the Special Drawing Rights (SDR) basket consolidated the internationalization of RMB. The rising role of RMB in the global currency markets is drawing more and more attention.

The Association of Southeast Asian Nations (ASEAN) is the priority and primary partner for China in promoting the B\&R Initiative. According to the statistics of the trade volume between China and its 59 trading partners along the Belt and Road (source: Wind Economic Database), during the period from January 1995 to June 2018, six of the top ten largest trade partners of China in the Belt and Road area were ASEAN countries. These six countries were Vietnam, Malaysia, Thailand, Singapore, Indonesia, and the Philippines. Given the increasing opportunities and the importance of cooperation 
between China and ASEAN, analyzing the interdependence between CNY and the currencies of major ASEAN countries has high significance. In the first place, it helps to identify the co-movement mechanism between currencies, gives indications for both China and ASEAN in terms of risk control and central bank interventions, and helps us to jointly foster a stable and healthy currency market environment in order to promote unimpeded trade and financial integration. Moreover, exploring the different dependence characteristics between the exchange rates of CNY and ASEAN currencies before and after the $B \& R$ Initiative helps us to understand the changing role of RMB in the regional currency markets, thus providing a useful reference to guide regional cooperation in a more sustainable, inclusive, and universally beneficial direction.

This paper investigates the interdependence between the exchange rates of $\mathrm{CNY}$ and the currencies of six major ASEAN countries, namely, Vietnam, Malaysia, Thailand, Singapore, Indonesia, and the Philippines (these countries are listed according to the descending order of their total trade volume with China from January 1995 to June 2018). These six countries accounted for $46 \%$ of the total trade volume between China and the B\&R countries up to the end of June 2018 (Source: Wind Economic Database). The five countries aside from Vietnam are the five founding fathers of ASEAN and play leading roles in terms of economic development and regional cooperation. Vietnam is also taken into consideration in this paper because in recent years its trade volume with China has been the largest among all the ASEAN countries.

The remainder of this paper is organized as follows: Section 2 reviews the literature and summarizes the contributions of our paper. Section 3 presents the summary statistics of the data and the basics of our research methodology. Section 4 presents the empirical results, and in Section 5 we draw our conclusions.

\section{Literature Review}

There are a great number of papers focusing on the "interdependence", "co-movements" or "linkage" between financial markets. As the RMB internationalization process accelerated, growing studies paid attention to the RMB exchange rate, and focused on investigating the dependence between the RMB exchange rate and other financial assets. For example, Lu et al. [1] studied cross-correlation behaviors between China's RMB exchange rate market and four international commodity markets. $\mathrm{Li}$ et al. [2] explored the dynamic relationship between the RMB exchange rate and the liquidity of the Shanghai and Shenzhen stock market. Ma and Wang [3] investigated the dependence structures between the prices of crude oil, natural gas, steam coal, and iron ore; the Australian dollar; and the RMB exchange rate. Meanwhile, there have been other studies that focused on the relationship between the RMB exchange rate and trade [4,5], the RMB exchange rate and other currencies [6,7], the inter-relationship between RMB markets [8-10], etc. In addition, many scholars have investigated the dependence or contagion between ASEAN currencies, such as McAleer and Nam [11], Muniandy and Uning [12], Sehgal et al. [13], etc. However, there have been few studies that focused on the interdependence between the Chinese RMB and the ASEAN currencies. Caporale et al. [14] investigated the linkages between ASEAN currencies and the RMB and the US dollar, and highlighted the increasingly important role of the RMB in ASEAN currency markets. To the best of our knowledge, no research has examined the dependence structure and its dynamic characteristics between the exchange rates of RMB and ASEAN currencies.

In regard to the research methods, different models and approaches have been developed to analyze the co-movements or interdependence between financial markets, such as Granger causality test and VAR model [8,15], generalized forecast error variance decomposition (GFEVD) and impulse response functions [16], dynamic conditional correlation-multivariate generalized autoregressive conditional heteroskedasticity (DCC-MGARCH) model $[17,18]$, and fractionally integrated asymmetric power ARCH-DCC (FIAPARCH-DCC) model [19]. Besides, Hu et al. [20] found that the causality-in-variance test has a better explanatory power for the co-movements of financial markets than the conventional 
GARCH-type model. However, these methods have limitations. As has been clearly stated, these methods cannot handle non-normal or heavy-tailed data [21,22].

To address this drawback, copula-GARCH models were applied to capture the dependence structure between financial assets [23-25]. Copula functions are joint distribution functions which are used for modeling the dependence structure between the marginal distributions of random variables [26]. The copula-GARCH models combine the use of GARCH models and copula functions to allow flexibility in the choice of marginal distributions and dependence structures. However, the standard bivariate and multivariate copulas were found to be inflexible in high-dimensional dependence modelling because they do not allow different dependence structures between different pairs of variables [27].

Vine copula models are flexible graphical models enabling extensions to higher dimensions using a cascade of bivariate copulas. They were found to be superior to the standard multivariate copulas, such as multivariate normal and multivariate-t copulas [28]. The vine approach is more flexible because we can select bivariate copulas from a wide range of (parametric) families. Moreover, vine copulas can also be used to measure non-conditional and conditional dependence structures, tail dependence, rank correlation, etc. Therefore, vine-copula GARCH models have gained increased attention for modeling high-dimensional dependence structures. There have been some further theoretical developments of vine copulas, in particular, Canonical vine (C-vine) copulas and drawable vine (D-vine) copulas. Compared with bivariate copula-GARCH models, vine copula-GARCH models have been widely used to study the interdependence of multivariate financial assets [29-31].

Based on prior researches, we use $\mathrm{C}$-vine copula model to investigate the interdependence between $\mathrm{CNY}$ and the currencies of ASEAN countries, and compare the differences in the dependence structure and degree between currencies before and after the B\&R Initiative. Compared with existing studies, the contributions of this paper are threefold. First, this paper compensates for the lack of academic studies on foreign exchange market interdependence between China and the ASEAN countries. Second, a C-vine copula approach is applied, which can not only be used to examine the interdependence between CNY and the currencies of ASEAN countries but can also be further applied to investigate the currency linkages between ASEAN countries conditional on CNY; thus, the role of RMB in ASEAN foreign exchange markets is in evidence from a systematic perspective. Third, differences in the dependence structure and degree between currencies over different timescales before and after the $B \& R$ Initiative are investigated, which helps to show the influence of the B\&R Initiative on co-movements in the foreign exchange markets of China and the ASEAN.

\section{Data and Methodology}

This section presents the descriptive statistics of the data and provides the basic theories of C-vine, static, and time-varying copulas, Kendall's tau correlation and its relationship with copulas, the sequential selection principle based on Kendall's tau, and the specification of marginal models.

\subsection{Data}

In this paper, we used the data of World Market Reuters (WM/R) exchange rates sourced from Thomson Financial DataStream. The observation period ranged from 3 August 2009 to 25 July 2018, and was roughly divided into the Pre-B\&R period and the Post- $B \& R$ period to capture the differences between before and after the $B \& R$ Initiative. In consideration of the fact that the $B \& R$ Initiative was considered as a national strategy as President $\mathrm{X} i$ Jinping urged the strategic planning of the Initiative at the annual Central Economic Work Conference of China in December 2013, we roughly defined the period from August 2009 to December 2013 to be the Pre-B\&R period. The period from January 2014 to July 2018 was then defined as the Post-B\&R period.

Weekly frequency data were applied for our study because they avoid any problems arising from time zone differences between China and the ASEAN countries. Meanwhile, they avoid problems related to drift and noise that would be present in daily or high-frequency data [30]. The weekly returns 
of exchange rates were calculated as the log-difference of the exchange rates, which were multiplied by 100 to be expressed as a percentage. The returns of exchange rates were calculated from the prices of one Chinese Yuan (CNY), Vietnamese Dong (VND), Malaysian Ringgit (MYR), Thai Baht (THB), Singapore Dollar (SGD), Indonesian Rupiah (IDR), and Philippine Peso (PHP) expressed in U.S. Dollars (USD), which are represented as USD/CNY, USD/VND, USD/MYR, USD/THB, USD/SGD, USD/IDR, and USD/PHP, respectively, so that positive values of return imply appreciation of the currency and vice versa.

The descriptive statistics of the currency return series are summarized in Table 1. All of the average exchange rate returns were close to zero. The volatility (SD) of the USD/MYR exchange rate was the greatest in both periods. All currency returns exhibited kurtosis and skewness, while most were not normally distributed based on the results of the Jarque-Bera test. The non-normality of the data should not be ignored, as we may draw invalid statistical inferences for skewed data if we still assume the data to be symmetrically or approximately normally distributed. Ignoring the non-normality of data could also lead to poor robustness of the estimation results [32].

Table 1. Descriptive statistics of the exchange rate returns. B\&R: Belt and Road; CNY: Chinese Yuan; VND: Vietnamese Dong; MYR: Malaysian Ringgit; THB: Thai Baht; SGD: Singapore Dollar; IDR: Indonesian Rupiah; PHP: Philippine Peso.

\begin{tabular}{|c|c|c|c|c|c|c|c|c|c|}
\hline & Mean & Median & Max. & Min. & SD & Skewne & Kurtosis & Jarque-Bera & Obs. \\
\hline \multicolumn{10}{|c|}{ Pre-B\&R period (3 August 2009 to 25 December 2013) } \\
\hline CNY & 0.05 & 0.01 & 0.77 & -0.43 & 0.19 & 0.45 & 4.22 & $21.95^{* * *}$ & 230 \\
\hline VND & -0.07 & 0.00 & 1.27 & -6.92 & 0.57 & -8.47 & 94.27 & $82575^{* * *}$ & 230 \\
\hline MYR & 0.03 & 0.03 & 2.63 & -3.15 & 0.89 & -0.15 & 3.21 & 1.28 & 230 \\
\hline THB & 0.02 & 0.03 & 1.93 & -1.74 & 0.68 & -0.21 & 3.48 & 3.91 & 230 \\
\hline SGD & 0.06 & 0.11 & 2.24 & -3.06 & 0.74 & -0.36 & 4.27 & $20.34^{* * *}$ & 230 \\
\hline IDR & -0.09 & -0.07 & 2.51 & -4.58 & 0.83 & -0.71 & 7.27 & $194.3^{* * *}$ & 230 \\
\hline PHP & 0.04 & 0.04 & 1.84 & -3.01 & 0.78 & -0.66 & 4.80 & $48.02^{* * *}$ & 230 \\
\hline \multicolumn{10}{|c|}{ Post-B\&R period (1 January 2014 to 25 July 2018) } \\
\hline CNY & -0.05 & -0.03 & 1.52 & -2.82 & 0.46 & -0.93 & 9.92 & $511.5^{* * *}$ & 239 \\
\hline VND & -0.04 & 0.00 & 0.69 & -1.67 & 0.23 & -2.38 & 17.03 & $2185.3^{* * *}$ & 239 \\
\hline MYR & -0.09 & -0.08 & 4.11 & -4.09 & 1.09 & 0.19 & 5.85 & $82.49^{* * *}$ & 239 \\
\hline THB & -0.01 & 0.00 & 2.33 & -2.55 & 0.62 & -0.31 & 5.08 & $46.97^{* * * *}$ & 239 \\
\hline SGD & -0.03 & -0.02 & 2.29 & -1.96 & 0.72 & 0.09 & 3.65 & 4.52 & 239 \\
\hline IDR & -0.07 & -0.12 & 5.80 & -2.81 & 0.97 & 1.16 & 8.94 & $405.4^{* * *}$ & 239 \\
\hline PHP & -0.08 & -0.05 & 1.52 & -1.89 & 0.56 & -0.13 & 3.66 & $4.97 *$ & 239 \\
\hline
\end{tabular}

Note: Significance at the $0.01,0.05$, and 0.10 levels indicated by ${ }^{* * *}, * * *$.

\subsection{Methodology}

In this paper, we applied the method of C-vine copulas to investigate the interdependence between CNY and the currencies of ASEAN countries. We used the inference function for margins (IFM) to estimate the C-vine copula model. The IFM method involves two stages: the first stage is using marginal models to get the marginal distributions of each return series; the second stage is to plug the marginal distributions into copula models to estimate the parameters of the C-vine copulas. Joe [33] proved that the estimator under the IFM method generally has good efficiency and is close to the maximum likelihood estimator under some regularity conditions. In this subsection, we present the basic theories of $\mathrm{C}$-vine copulas and other related techniques.

\subsubsection{Canonical Vine (C-Vine) Copulas}

A copula is a mathematical function used to join univariate distribution functions to form joint (multivariate) distribution functions. To build a multivariate model, we can first model the marginals 
and then model their dependence structure via a copula. Sklar's theorem gave the first definition of a copula: a copula is a "joint probability measure" which describes the dependence structure between the variables. Any multivariate joint distribution can be written in terms of univariate marginal distribution functions and a copula. Let $X=\left(X_{1}, X_{2}, \ldots, X_{n}\right)$ be a random vector with marginal distribution $F_{1}\left(x_{1}\right), F_{2}\left(x_{2}\right), \ldots, F_{n}\left(x_{n}\right)$; then there exists a function called a copula such that:

$$
H\left(x_{1}, x_{2}, \ldots, x_{n}\right)=C\left(F_{1}\left(x_{1}\right), F_{2}\left(x_{2}\right), \ldots, F_{n}\left(x_{n}\right)\right) .
$$

The copula function in (1) can also be expressed as:

$$
C\left(u_{1}, u_{2}, \ldots, u_{n}\right)=H\left(F_{1}^{-1}\left(u_{1}\right), F_{2}^{-1}\left(u_{2}\right), \ldots, F_{n}^{-1}\left(u_{n}\right)\right) .
$$

Given that $F_{i}$ is absolutely continuous and strictly increasing, the probability density function of $X$ can be factorized as:

$$
f\left(x_{1}, x_{2}, \ldots, x_{n}\right)=\frac{\partial H\left(x_{1}, x_{2}, \ldots, x_{n}\right)}{\partial x_{1} \ldots \partial x_{n}}=\frac{\partial C\left(u_{1}, u_{2}, \ldots, u_{n}\right)}{\partial u_{1} \ldots \partial u_{n}} \times \Pi \frac{\partial F_{i}\left(x_{i}\right)}{\partial x_{i}}=c\left(u_{1}, u_{2}, \ldots, u_{n}\right) \times \Pi f_{i}\left(x_{i}\right) .
$$

Bedford and Cooke [34] proposed the vine copula approach, which is also called a pair-copula construction (PCC) as systematically introduced by Aas et al. [35]. Taking a three-dimensional system as an example, a vine representation of Equation (3) is:

$$
\begin{aligned}
& f\left(x_{1}, x_{2}, x_{3}\right)=f_{1}\left(x_{1}\right) \cdot f_{2}\left(x_{2}\right) \cdot f_{3}\left(x_{3}\right) \\
& \cdot c_{12}\left(F_{1}\left(x_{1}\right), F_{2}\left(x_{2}\right)\right) \cdot c_{13}\left(F_{1}\left(x_{1}\right), F_{3}\left(x_{3}\right)\right) \\
& \cdot c_{23 \mid 1}\left(F_{2 \mid 1}\left(x_{2} \mid x_{1}\right), F_{3 \mid 1}\left(x_{3} \mid x_{1}\right)\right),
\end{aligned}
$$

where $c_{12}$ is an appropriate pair-copula density for the pair of transformed variables $F_{1}\left(x_{1}\right)$ and $F_{2}\left(x_{2}\right)$, and $c_{13}$ is analogous. The pair-copula $c_{23 \mid 1}$ is applied to the conditional cumulative distribution functions (cdfs) $F_{2 \mid 1}\left(x_{2} \mid x_{1}\right)$ of $x_{2}$ given $x_{1}$ and $F_{3 \mid 1}\left(x_{3} \mid x_{1}\right)$ of $x_{3}$ given $x_{1}$, where the two arguments are defined by:

$$
F_{i \mid j}\left(x_{i} \mid x_{j}\right)=\frac{\partial C_{i j}\left(F_{i}\left(x_{i}\right), F_{j}\left(x_{j}\right)\right)}{\partial F_{j}\left(x_{j}\right)}=\frac{\partial C_{i j}\left(u_{i}, u_{j}\right)}{\partial u_{j}} .
$$

We can then write the log-likelihood function of Equation (4) as follows:

$$
\begin{aligned}
& l\left(\theta^{m}, \theta^{c} ; \mathbf{x}\right)=\sum_{i=1}^{3} \sum_{t=1}^{T} \log f_{i}\left(x_{i t} ; \theta_{i}^{m}\right) \\
& +\sum_{t=1}^{T} c_{12}\left(F_{1}\left(x_{1 t} ; \theta_{1}^{m}\right), F_{2}\left(x_{2 t} ; \theta_{2}^{m}\right) ; \theta_{12}^{c}\right)+\sum_{t=1}^{T} c_{13}\left(F_{1}\left(x_{1 t} ; \theta_{1}^{m}\right), F_{3}\left(x_{3 t} ; \theta_{3}^{m}\right) ; \theta_{13}^{c}\right) \\
& +\sum_{t=1}^{T} c_{23 \mid 1}\left(F_{2 \mid 1}\left(x_{2 t} \mid x_{1 t} ; \theta_{1}^{\mathrm{m}}, \theta_{2}^{\mathrm{m}}, \theta_{12}^{c}\right), F_{3 \mid 1}\left(x_{3 t} \mid x_{1 t} ; \theta_{1}^{\mathrm{m}}, \theta_{3}^{\mathrm{m}}, \theta_{13}^{c}\right) ; \theta_{23 \mid 1}^{c}\right)
\end{aligned}
$$

where $\theta^{m}=\left(\left(\theta_{1}^{m}\right)^{\prime},\left(\theta_{2}^{m}\right)^{\prime},\left(\theta_{3}^{m}\right)^{\prime}\right)^{\prime}$ denotes a parameter vector estimated from the marginal models, and $\theta^{c}=\left(\left(\theta_{12}^{c}\right)^{\prime},\left(\theta_{13}^{c}\right)^{\prime},\left(\theta_{23 \mid 1}^{c}\right)^{\prime}\right)$ is a parameter vector estimated from three bivariate copulas [30].

The bivariate pair-copulas $c_{12}, c_{13}$, and $c_{23 \mid 1}$ can be chosen independently of each other by using model selection criteria such as the Akaike Information Criterion (AIC) and the Bayesian Information Criterion (BIC). The dependence structures of a three-dimensional vine can thus be modeled using PCCs; the structure of a higher-dimensional vine is constructed in the same way.

Suppose there are $d$ univariate variables. Vine copulas arrange $d(d-1) / 2$ pair-copulas in $d-1$ linked trees for a $d$-dimensional pair-copula construction. A C-vine is a special case of the vine copula. In the first tree of a $\mathrm{C}$-vine, the dependence is modeled using bivariate copulas for each pair of variables with respect to one unique variable, which is the first root node of the $\mathrm{C}$-vine tree. Conditioned on this variable, in the second tree, pairwise dependencies with respect to a second variable (which is the second root node) are modeled. Brechmann and Czado [36] stated that C-vine copulas are appropriate 
to apply only if there is a pivotal variable among the variables under consideration; otherwise, the tree structure of a $\mathrm{C}$-vine may be too restrictive. An example of a four-dimensional $\mathrm{C}$-vine structure is shown in Figure 1.

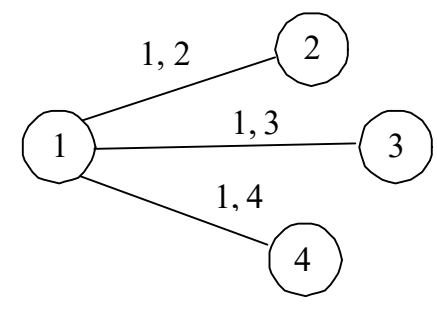

$\mathrm{T} 1$

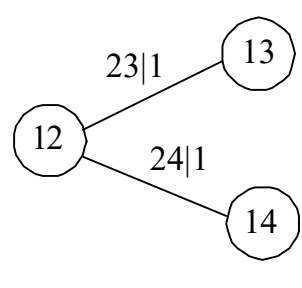

$\mathrm{T} 2$

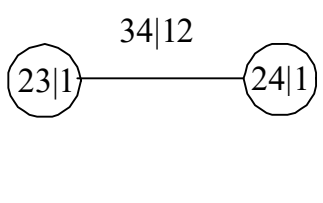

$\mathrm{T} 3$

Figure 1. Example of four-dimensional Canonical vine (C-vine) trees with edge indices.

\subsubsection{Nonlinear Correlation and Tail Dependence}

Kendall's tau is a rank correlation measure that can be described as the probability of concordance minus the probability of discordance of two pairs of random variables [37]. The empirical Kendall's tau coefficient $\tau$ is defined as:

$$
\tau(X, Y)=P\left[\left(X-X^{\prime}\right)\left(Y-Y^{\prime}\right)>0\right]-P\left[\left(X-X^{\prime}\right)\left(Y-Y^{\prime}\right)<0\right],
$$

where $(X, Y)$ and $\left(X^{\prime}, Y^{\prime}\right)$ are two independent and identically distributed pairs of random variables. Kendall's tau can be expressed in terms of a copula function as follows:

$$
\tau_{X, Y}=4 \iint_{I^{2}} C(u, v) d C(u, v)-1=1-4 \iint_{I^{2}} \frac{\partial C}{\partial u}(u, v) \frac{\partial C}{\partial v}(u, v) d u d v
$$

where $C$ is the copula function, and $u$ and $v$ are the values of marginal distribution functions.

The upper (lower) tail dependence gives the probability that two variables jointly take extreme positive (negative) values [25]. The upper tail dependence $\lambda_{U}$ and lower tail dependence $\lambda_{L}$ are expressed as:

$$
\begin{gathered}
\lambda_{U}=\lim _{u \rightarrow 1} P\left[Y>G_{Y}^{-1}(u) \mid X>F_{X}^{-1}(u)\right]=\lim _{u \rightarrow 1} \frac{1-2 u+C(u, u)}{1-u}, \\
\lambda_{L}=\lim _{u \rightarrow 0} P\left[Y \leq G_{Y}^{-1}(u) \mid X \leq F_{X}^{-1}(u)\right]=\lim _{u \rightarrow 0} \frac{C(u, u)}{u},
\end{gathered}
$$

where $F$ and $G$ are the marginal cumulative distribution functions of $X$ and $Y$. The copula exhibits an upper tail dependence coefficient when $\lambda_{U} \in(0,1]$ and exhibits a lower tail dependence coefficient when $\lambda_{L} \in(0,1]$.

\subsubsection{Specification of Copulas}

The bivariate copulas employed in this study include Gaussian, Frank, Clayton and Rotated Clayton 90 degrees, survival BB8 (Joe-Frank), and Joe copulas. Different copulas capture dependence in different ways. The Gaussian copulas belong to the elliptical copulas. The Frank, (rotated) Clayton, Joe, and (survival) BB8 copulas belong to a more general family of copulas called the Archimedean copulas. Archimedean copulas admit an explicit formula and are widely used in applications due to their simple forms and favorable properties. The Gaussian, Frank, Clayton, and Joe copulas all have only one parameter, while the BB8 copulas have two parameters.

The copulas in this study have different tail dependence structures: the Gaussian copula and Frank copula have no tail dependence. The Joe copula has only upper tail dependence, while the Clayton copula is asymmetric with lower tail dependence. The Clayton copula cannot display negative dependencies. In real-world problems, the correlations between financial series are not always 
positive; it is also possible to notice negative dependencies between financial variables. Copula rotation allows us to transform copulas such that they can be used to model negative dependence; see details in Sriboonchitta et al. [22] for the rotated versions of different copulas and their densities. The rotated Clayton copula (90 degrees) can model negative dependence-it has no upper and lower tail dependence. The BB8 copula is also called the Joe-Frank copula; the BB8 copula and survival BB8 copula (rotated 180 degrees) have zero tail dependence if the second parameter $\delta$ of the copula is nonzero. Detailed expressions of the functions of copulas, functions to compute Kendall's tau correlations from copulas, and functions of the lower and upper tail dependence can be found in Brechmann et al. [36] and Sriboonchitta et al. [22].

The nature of a copula can either be static or time-variant. The dynamic characteristics of dependence across markets can help policy-makers understand co-movement between markets more clearly. In this study, time-varying copulas were adopted to follow the autoregressive moving average (ARMA) $(1,1)$ process.

The time-varying correlation for a Gaussian or Frank copula has the following form:

$$
\theta_{t}=\widetilde{\Lambda}\left\{\varphi_{0}+\varphi_{1} \theta_{t-1}+\varphi_{2}\left(u_{t-1}-0.5\right)\left(v_{t-1}-0.5\right)\right\},
$$

where $\widetilde{\Lambda}=\left(1-e^{-x}\right) /\left(1+e^{-x}\right)$ is the logistic transformation used to restrict the time-varying correlation coefficients $\theta_{t}$ to be in the range $(-1,1)$. The autoregressive term $\varphi_{1} \theta_{t-1}$ captures the persistence effect, while $\varphi_{2}\left(u_{t-1}-0.5\right)\left(v_{t-1}-0.5\right)$ captures the variation effect in dependence.

The form of a time-varying Clayton or Joe copula is expressed as:

$$
\theta_{t}=\Lambda\left\{\varphi_{0}+\varphi_{1} \theta_{t-1}+\varphi_{2}\left(u_{t-1}-0.5\right)\left(v_{t-1}-0.5\right)\right\}
$$

where $\Lambda=\left(1+e^{-x}\right)^{-1}$ guarantees that the parameter $\theta_{t}$ will lie in the range $(0,1)$.

The BB8 copula consists of two dependence parameters, and both parameters are assumed to be time-variant:

$$
\begin{aligned}
& \theta_{t}=H\left\{\varphi_{0}+\varphi_{1} \theta_{t-1}+\varphi_{2}\left(u_{t-1}-0.5\right)\left(v_{t-1}-0.5\right)\right\}, \\
& \delta_{t}=H\left\{\varphi_{3}+\varphi_{4} \delta_{t-1}+\varphi_{5}\left(u_{t-1}-0.5\right)\left(v_{t-1}-0.5\right)\right\},
\end{aligned}
$$

where $H$ is an appropriate logistic transformation function.

\subsubsection{Specification of Marginal Models}

In this paper, the marginal distribution of each exchange rate series was characterized by an $\operatorname{ARMA}(\mathrm{p}, \mathrm{q})$-Glosten-Jagannathan-Runkle(GJR)-GARCH$(1,1)$ model with a disturbance term following the skewed normal distribution (snorm), skewed Student $t$ distribution (sstd), or skewed generalized error distribution (sged). Assumptions of normality are usually violated in real-world problems, as data possess skewness; an extra skewness (or shape) parameter can be used to fit various types of skewed data $[38,39]$. The values of skewness and kurtosis in Table 1 show that our data were skewed and leptokurtic. Moreover, the Jarque-Bera test statistic was large and significant for most series; therefore, the assumption of skewed distributions was more appropriate in our study. Conditional mean models were selected among four lag orders $(\operatorname{ARMA}(0,0), \operatorname{ARMA}(1,0), \operatorname{ARMA}(0,1), \operatorname{ARMA}(1,1))$. The best-fitting marginal models were selected according to the BIC. The form of the ARMA(p,q)-GJR-GARCH $(1,1)$ model can be expressed as:

$$
\begin{gathered}
r_{t}=\mu+\sum_{i=1}^{p} \phi_{1 i} r_{t-i}+\sum_{j=1}^{q} \phi_{2 j} \varepsilon_{t-j}+\varepsilon_{t}, \\
\varepsilon_{t}=\sigma_{t} \cdot \eta_{t}, \\
\sigma_{t}^{2}=\omega+\alpha \varepsilon_{t-1}^{2}+\beta \sigma_{t-1}^{2}+\gamma I\left[\varepsilon_{t-1}<0\right] \varepsilon_{t-1}^{2},
\end{gathered}
$$


where $\sum_{i=1}^{p} \phi_{1 i}<1, \omega>0, \alpha \geq 0, \beta \geq 0, \alpha+\gamma \geq 0$ and $\alpha+\beta+\frac{1}{2} \gamma<1$.

Equation (15) is the so-called mean equation, where $r_{t}$ is the return series of the exchange rate and $\phi_{1 i}$ and $\phi_{2 i}$ are the coefficients of the AR and MA terms. Equation (16) shows that the residual $\varepsilon_{t}$ is the product of the standard variance $\sigma_{t}$ and standardized residuals $\eta_{t}$. Equation (17) is the variance equation, where parameters $\alpha$ and $\beta$ are the coefficients of the ARCH term and GARCH term, the leverage effect is measured by $\gamma$, and variable $I$ is a dummy variable which is only activated if the previous shock $\varepsilon_{t-1}$ is negative. The leverage effect indicates that losses have a greater impact on future volatility than gains. If a leverage effect exists, the estimated parameter $\gamma$ needs to be positive $[39,40]$.

\subsubsection{Sequential Selection Based on Kendall's Tau Correlations}

After getting the marginals of each variable, the next step is to decide the order of the variables in the C-vine tree. In this paper, the USD/CNY exchange rate was selected to be the first node of the first $\mathrm{C}$-vine tree. In this way, the dependence between CNY and each currency of the ASEAN countries could be investigated using bivariate copulas, since we wanted to explore the role and power of CNY in the regional currency markets.

The order of the other six variables in the C-vine tree was decided by maximizing the sum of the absolute empirical Kendall's tau values of one variable with all the other variables. For instance, for the VND exchange rates, the sum of the absolute empirical Kendall's tau $\tau_{V N D}$ of variable pairs VND and CNY, VND and MYR, VND and THB, VND and SGD, VND and IDR, and VND and PHP had to be calculated. Similarly, the sum of the absolute empirical Kendall's tau values of other variables could be determined. After that, we reordered the remaining variables and repeated the process of calculating the sum of the Kendall's tau values, thus determining the order of all variables. By this rule, the order of variables in the C-vine tree was determined, with 1, 2, 3, 4, 5, 6, and 7, in proper turn, representing the exchange rate return series of CNY, MYR, SGD, IDR, THB, PHP, and VND; this indicates that MYR was the second root node of the $\mathrm{C}$-vine tree, and the pair-copulas in the second tree modeled the dependence of SGD, IDR, THB, PHP, and VND on MYR given CNY. The best-fitting bivariate copulas in every $\mathrm{C}$-vine tree were selected from a set of copulas according to the BIC.

\section{Empirical Results}

In this section, we present the empirical results of the marginal models, static C-vine copulas, and time-varying C-vine copulas. We further verify whether or not the results from the time-varying $\mathrm{C}$-vine copulas are consistent with conclusions from the static C-vine copulas.

\subsection{Marginal Estimations}

The estimation results from the marginal models are shown in Table 2. From the results of the mean equation, the exchange rate returns of the last week were found to have a significant positive influence on the returns of the current week for all the marginal models which contain AR $\left(\phi_{1}\right)$ terms. From the coefficients of the MA $\left(\phi_{2}\right)$ terms, the volatility of residuals from the last week was found to have significant negative effects on the currency returns in the current period.

The results of the variance equation showed that long-run volatility persistence (measured by the $\beta$ coefficient) was statistically significant for all variables, which means that the volatility of exchange rate returns in the current period was positively affected by the volatility of the last period; this provides evidence for the phenomenon of "volatility clustering" in the returns of the seven currencies. The coefficients of the GARCH term $\beta$ were much bigger than those of the ARCH term $\alpha$, indicating that the effects of the volatility shocks fade away slowly. 
Table 2. Estimation results for the marginal models of exchange rate returns.

\begin{tabular}{|c|c|c|c|c|c|c|c|}
\hline & CNY & VND & MYR & ТHB & SGD & IDR & PHP \\
\hline \multicolumn{8}{|c|}{ Pre-B\&R period (3 August 2009 to 25 December 2013) } \\
\hline Dist & sstd & sged & snorm & sged & snorm & sstd & sged \\
\hline \multirow[t]{2}{*}{$\mu$} & 0.003 & $-0.001^{* * *}$ & 0.054 & $0.061^{* *}$ & 0.059 & -0.087 & 0.033 \\
\hline & $(0.007)$ & $(<0.0001)$ & $(0.059)$ & $(0.028)$ & $(0.044)$ & $(0.191)$ & $(0.021)$ \\
\hline \multirow{2}{*}{$\phi_{1}$} & $0.997^{* * *}$ & & & $0.561^{* * *}$ & & $0.993^{* * *}$ & \\
\hline & $(0.007)$ & & & $(0.116)$ & & $(0.013)$ & \\
\hline \multirow[t]{2}{*}{$\phi_{2}$} & $-0.970 * * *$ & & & $-0.468^{* * *}$ & & $-0.962^{* * *}$ & \\
\hline & $(0.013)$ & & & $(0.121)$ & & $(0.024)$ & \\
\hline \multirow[t]{2}{*}{$\omega$} & 0.0002 & $0.0003^{* * *}$ & 0.073 & 0.016 & 0.061 & $0.057 *$ & 0.006 \\
\hline & $(0.0001)$ & $(<0.0001)$ & $(0.056)$ & (0.015) & (0.038) & $(0.030)$ & (0.005) \\
\hline \multirow[t]{2}{*}{$\alpha$} & $0.278^{* * *}$ & $0.056^{* * *}$ & 0.070 & 0.084 & 0.000 & $0.358 * *$ & 0.000 \\
\hline & $(0.067)$ & $(0.0004)$ & $(0.069)$ & $(0.057)$ & $(0.071)$ & $(0.173)$ & $(0.002)$ \\
\hline \multirow[t]{2}{*}{$\beta$} & $0.724^{* * *}$ & $0.942^{* * * *}$ & $0.841^{* * *}$ & $0.874^{* * *}$ & $0.788^{* * *}$ & $0.578^{* * *}$ & $1.000^{* * *}$ \\
\hline & $(0.048)$ & $(0.008)$ & $(0.084)$ & $(0.060)$ & $(0.095)$ & $(0.102)$ & $(<0.0001)$ \\
\hline \multirow[t]{2}{*}{$\gamma$} & -0.006 & $-0.047^{* * *}$ & -0.006 & 0.045 & 0.187 & 0.124 & -0.019 \\
\hline & $(0.104)$ & $(0.0001)$ & $(0.079)$ & $(0.075)$ & $(0.124)$ & $(0.234)$ & $(0.011)$ \\
\hline \multirow[t]{2}{*}{ Skew } & $1.147^{* * *}$ & $0.994^{* * *}$ & $0.959^{* * *}$ & $1.031^{* * *}$ & $0.828^{* * *}$ & $1.025^{* * *}$ & $0.989 * * *$ \\
\hline & $(0.079)$ & $(0.002)$ & $(0.092)$ & $(0.048)$ & $(0.079)$ & $(0.092)$ & $(0.047)$ \\
\hline \multirow[t]{2}{*}{ Shape } & $4.728^{* * *}$ & $0.313^{* * *}$ & & $1.209^{* * *}$ & & $3.566^{* * *}$ & $1.183^{* * *}$ \\
\hline & $(1.004)$ & $(0.001)$ & & $(0.178)$ & & $(0.699)$ & $(0.150)$ \\
\hline $\mathrm{BIC}$ & -174.505 & -311.445 & 625.542 & 488.532 & 516.821 & 506.004 & 555.424 \\
\hline \multicolumn{8}{|c|}{ Post-B\&R period (1 January 2014 to 25 July 2018) } \\
\hline \multirow{3}{*}{$\begin{array}{c}\text { Dist } \\
\mu\end{array}$} & sstd & sged & sged & sstd & sged & sged & sstd \\
\hline & -0.028 & 0.000 & -0.0007 & 0.009 & -0.043 & $-0.049 * *$ & $-0.033^{* * *}$ \\
\hline & $(0.034)$ & $(<0.0001)$ & $(0.103)$ & $(0.041)$ & $(0.044)$ & $(0.023)$ & $(0.0006)$ \\
\hline \multirow[t]{2}{*}{$\phi_{1}$} & $0.764^{* * *}$ & & $0.191^{* * *}$ & & & & \\
\hline & $(0.130)$ & & $(0.042)$ & & & & \\
\hline$\phi_{2}$ & $\begin{array}{c}-0.649^{* * *} \\
(0.147)\end{array}$ & & & & & & \\
\hline \multirow[t]{2}{*}{$\omega$} & 0.002 & $0.021^{* * *}$ & 0.018 & $0.303^{* *}$ & 0.002 & 0.033 & $0.019 * * *$ \\
\hline & $(0.003)$ & $(0.0004)$ & $(0.020)$ & $(0.120)$ & $(0.025)$ & (0.030) & $(<0.0001)$ \\
\hline \multirow[t]{2}{*}{$\alpha$} & $0.070^{* * *}$ & $1.0 \mathrm{E}-06$ & 0.049 & 0.148 & 0.000 & $0.116^{*}$ & $0.084^{* * *}$ \\
\hline & $(0.024)$ & $(<0.0001)$ & $(0.059)$ & $(0.208)$ & $(0.104)$ & $(0.059)$ & $(0.0005)$ \\
\hline \multirow[t]{2}{*}{$\beta$} & $0.954^{* * *}$ & $0.989^{* * *}$ & $0.878^{* * *}$ & 0.093 & $0.964^{* * *}$ & $0.740^{* * *}$ & $0.953 * * *$ \\
\hline & $(0.025)$ & $(0.004)$ & $(0.062)$ & $(0.244)$ & $(0.123)$ & $(0.061)$ & $(0.006)$ \\
\hline \multirow[t]{2}{*}{$\gamma$} & -0.051 & $0.021^{* * *}$ & 0.117 & 0.094 & 0.068 & $0.268^{* *}$ & $-0.163^{* * *}$ \\
\hline & $(0.031)$ & $(0.0007)$ & $(0.093)$ & $(0.235)$ & $(0.051)$ & $(0.107)$ & $(0.0001)$ \\
\hline \multirow[t]{2}{*}{ Skew } & $0.987^{* * *}$ & $0.999^{* * *}$ & $1.113^{* * *}$ & $0.961^{* * *}$ & $0.891^{* * *}$ & $1.102^{* * *}$ & $0.993^{* * *}$ \\
\hline & $(0.085)$ & $(0.0009)$ & $(0.115)$ & $(0.079)$ & $(0.005)$ & $(0.043)$ & $(0.091)$ \\
\hline \multirow[t]{2}{*}{ Shape } & $3.154^{* * *}$ & $0.179^{* * *}$ & $1.244^{* * *}$ & $3.910^{* * *}$ & $1.479^{* * *}$ & $1.067^{* * *}$ & $7.738^{* *}$ \\
\hline & $(0.505)$ & $(0.003)$ & $(0.161)$ & $(1.225)$ & $(0.198)$ & $(0.116)$ & $(3.886)$ \\
\hline BIC & 249.694 & -321.425 & 670.645 & 445.337 & 537.907 & 606.860 & 421.685 \\
\hline
\end{tabular}

Note: Significance at the $0.01,0.05$, and 0.10 levels indicated by $* * * * *, *$; Standard errors in parentheses. BIC: Bayesian Information Criterion; sgred: skewed generalized error distribution; ssnorm: skewed normal distribution; sstd: skewed Student $t$ distribution.

All of the return series except that for the Malaysian Ringgit in the Pre-B\&R period were specified by either a skewed Student $t$ distribution or a skewed generalized error distribution, while the return series of MYR in the Pre-B\&R period was best captured by a skewed normal distribution according to the BIC. The coefficients of the GJR term $(\gamma)$ were significantly positive for variables VND and IDR in the Post-B\&R period, suggesting that leverage effects were present in the exchange rate returns of the Vietnamese Dong and Indonesian Rupiah. The leverage effects showed asymmetric volatility of the exchange rate returns. A fall in the returns of these two exchange rates will have a greater impact on volatility than an increase in the returns. Thus, if the exchange rates go down, the returns 
of the exchange rates will tend to be more unstable and lead to higher risks in the foreign exchange markets. The skewness and shape parameters were estimated to be statistically significant in all return series, which further indicated that the distributions of these return series were not symmetric. The skewed distributions we used in the estimation of the marginal models were more proper than normal distributions to account for the skewness and kurtosis in our data.

\subsection{Estimation Results of the Static C-Vine Copulas}

The estimation results of the static C-vine copulas for before and after the B\&R Initiative are reported in Table 3. The results present the selected copula families (Copulas) according to the BIC, the estimates of copula parameters (Par), the implied estimates of Kendall's tau (Tau), and tail dependence (Tail dep) in the first and second trees. Note that the parameter ranges of the bivariate copula families are different, so the dependence degree cannot be compared directly from the copula parameters. However, since Kendall's tau correlation has a direct relation to the copula function from Equation (8), we can extract Kendall's tau from a copula and compare the degree of dependence between exchange rates through the values of Kendall's tau.

\subsubsection{The Interdependence between CNY and the Currencies of Major ASEAN Countries}

The first $\mathrm{C}$-vine tree reflects the degree and structure of dependence between the returns of CNY and the currencies of six ASEAN countries-MYR, SGD, IDR, THB, PHP, and VND.

Most of the copula parameters were estimated to be positive and significant in both periods, which implies positive interdependence between CNY and the currencies of the ASEAN countries. In terms of dependence degree, the estimated values of Kendall's tau in the first C-vine tree were almost positive over both periods, except for that for the CNY-VND pair in the Pre-B\&R period. This implies that the returns of CNY are positively correlated with the returns of the ASEAN currencies and provides evidence of co-movements between the exchange rates of CNY and the currencies of major ASEAN countries. In 2009, the cross-border yuan trade settlement pilot scheme was launched in Shanghai, China, which is identified as the starting point of RMB internationalization. The China-ASEAN Free Trade Area (CAFTA) was realized soon afterward in 2010, which stimulated China's exports to ASEAN countries [41]. This resulted in an increasingly significant role of RMB in regional trade and contributed to the co-movement phenomenon between the currency markets of China and the ASEAN. It is noteworthy that compared with the Pre-B\&R period, the values of Kendall's tau in the first C-vine tree all increased obviously in the Post-B\&R period, which indicates that the degree of dependence between CNY and the currencies of ASEAN countries increased obviously after the B\&R Initiative began. The B\&R Initiative further opened up huge opportunities for gainful co-operation in trade and investment between China and the ASEAN, and it promoted the adoption of the RMB as the reserve and settlement currency by $B \& R$ countries. The noticeably increased degree of positive dependence between the exchange rates of CNY and ASEAN currencies in the Post-B\&R period is reasonable.

In both periods, the dependence degree of CNY and SGD was the highest among all six currency pairs, followed by CNY and THB and by CNY and MYR. This result is to some extent consistent with the finding by Bloomberg News [42], which announced that the Singapore Dollar had the strongest link to the Yuan among the 12 currencies they examined; about 41 percent of fluctuations in the Singapore dollar from 2017 to 2018 could be explained by changes in the offshore Yuan. Trade is a crucial factor for Singapore's economic growth. Singapore became China's largest investor country in 2013, and it became China's third-largest trading partner and largest overseas direct investment destination in the ASEAN in 2014. In 2014, China announced direct trading between CNY and SGD, and with Singapore as the main trade finance hub for the Asia-Pacific region, Singapore emerged as another dominant offshore RMB hub alongside Hong Kong. It is therefore no wonder that the dependence between CNY and SGD was the highest. However, the values of the Kendall's tau coefficients were not big, which indicates limited correlations between CNY and the ASEAN currencies, so the power of CNY's influence on ASEAN foreign exchange markets is still limited. 
Table 3. Estimation results from the static C-vine copulas.

\begin{tabular}{|c|c|c|c|c|c|c|c|}
\hline & Pairs & Copulas & Par & Se & Tau & Tail dep & BIC \\
\hline \multicolumn{8}{|c|}{ Pre-B\&R period (3 August 2009 to 25 December 2013) } \\
\hline \multirow{6}{*}{ Tree1 } & CNY-MYR & Gaussian & $0.206^{* * *}$ & 0.049 & 0.132 & 0.000 & -16.50 \\
\hline & CNY-SGD & Frank & $1.479^{* * *}$ & 0.351 & 0.161 & 0.000 & -14.73 \\
\hline & CNY-IDR & Frank & $1.063^{* * *}$ & 0.365 & 0.117 & 0.000 & -7.66 \\
\hline & CNY-THB & Frank & $1.231^{* * *}$ & 0.365 & 0.135 & 0.000 & -9.21 \\
\hline & CNY-PHP & Gaussian & 0.074 & 0.054 & 0.048 & 0.000 & 1.27 \\
\hline & CNY-VND & $\begin{array}{c}\text { Clayton } \\
90^{\circ}\end{array}$ & -0.054 & 0.047 & -0.026 & 0.000 & 4.27 \\
\hline \multirow{6}{*}{ Tree2 } & MYR-SGD|CNY & Frank & $6.294^{* * *}$ & 0.538 & 0.529 & 0.000 & -150.8 \\
\hline & MYR-IDR|CNY & Gaussian & $0.578^{* * *}$ & 0.038 & 0.392 & 0.000 & -90.43 \\
\hline & MYR-THB|CNY & $\begin{array}{c}\text { Survival } \\
\text { BB8 }\end{array}$ & $3.078^{* * *}$ & 0.705 & 0.411 & 0.000 & -93.86 \\
\hline & & & $0.868^{* * *}$ & 0.090 & & & \\
\hline & MYR-PHP|CNY & Gaussian & $0.701^{* * *}$ & 0.027 & 0.495 & 0.000 & -147.8 \\
\hline & MYR-VND|CNY & Joe & $1.125^{* * *}$ & 0.066 & 0.067 & $0.149[\mathrm{U}]$ & 0.841 \\
\hline \multicolumn{8}{|c|}{ Post-B\&R period (1 January 2014 to 25 July 2018) } \\
\hline \multirow{6}{*}{ Tree1 } & CNY-MYR & Gaussian & $0.328^{* * *}$ & 0.050 & 0.213 & 0.000 & -31.43 \\
\hline & CNY-SGD & Frank & $2.568^{* * *}$ & 0.400 & 0.268 & 0.000 & -41.27 \\
\hline & CNY-IDR & Clayton & $0.377^{* * *}$ & 0.081 & 0.159 & $0.159[\mathrm{~L}]$ & -27.76 \\
\hline & CNY-THB & Gaussian & $0.306^{* * *}$ & 0.051 & 0.198 & 0.000 & -26.35 \\
\hline & CNY-PHP & Clayton & $0.272^{* * *}$ & 0.078 & 0.120 & $0.078[\mathrm{~L}]$ & -11.76 \\
\hline & CNY-VND & Gaussian & $0.156^{* *}$ & 0.061 & 0.100 & 0.000 & -3.133 \\
\hline \multirow{5}{*}{ Tree2 } & MYR-SGD|CNY & Gaussian & $0.614^{* * *}$ & 0.035 & 0.421 & 0.000 & -103.9 \\
\hline & MYR-IDR|CNY & Frank & $3.971^{* * *}$ & 0.436 & 0.386 & 0.000 & -77.66 \\
\hline & MYR-THB|CNY & Gaussian & $0.455^{* * *}$ & 0.048 & 0.301 & 0.000 & -48.66 \\
\hline & MYR-PHP|CNY & Frank & $2.463^{* * *}$ & 0.411 & 0.259 & 0.000 & -33.18 \\
\hline & MYR-VND|CNY & Clayton & $0.211^{* *}$ & 0.084 & 0.095 & $0.037[\mathrm{~L}]$ & -1.396 \\
\hline
\end{tabular}

Note: Due to length limitations, we only report the estimate results of the first and second trees of the C-vine copulas; Significance at the $0.01,0.05$, and 0.10 levels indicated by ${ }^{* * *}, * *$, and $*$; Standard errors in parentheses; The symbol "[U]" represents upper tail dependence, "[L]" represents lower tail dependence.

As for the dependence structure, in the Pre-B\&R period, the fitting pair-copula families were Gaussian, Frank, and Clayton Rotated 90 degrees. Gaussian and Frank copulas both featured symmetry without tail dependence; this implies that the dependence structures of CNY and MYR, CNY and SGD, CNY and IDR, and CNY and THB are symmetric, and there is thus no evidence for asymmetric co-movements between large losses (gains) of CNY and these four currencies. Furthermore, no conclusion was supported for the CNY-PHP and CNY-VND pairs, since the copula parameters for these two pairs were not significant. However, changes happened in the Post-B\&R period: the fitting pair-copula family of CNY-IDR and CNY-PHP changed to be Clayton with only lower tail dependence, which indicates that the potential for CNY and IDR to jointly depreciate against USD is higher than the potential for co-movements when they jointly appreciate, with the same conclusion being made for $\mathrm{CNY}$ and PHP. Systematic risk caused by the asymmetry property in the currency markets of China and the ASEAN deserves attention. Following the B\&R Initiative, China increased investment overseas and provided loans to foreign governments to fund infrastructure projects; the tightening economic and financial ties between China and B\&R countries increase the possibility of contagion when extreme situations occur.

\subsubsection{Interdependence between the Currencies of Major ASEAN Countries Conditional on CNY}

Next, we explored the dependence between the currencies of ASEAN countries conditional on the returns of CNY, which corresponds to the second tree of the C-vine copulas. 
Given the returns of CNY, the values of Kendall's tau in the second tree reflect the conditional dependence between MYR and the other five ASEAN currencies. The values of Kendall's tau in the second tree were comparatively larger than those in the first tree, which implies that the return of MYR is more relevant to the currencies of ASEAN countries than CNY and plays an important role in the stability of ASEAN foreign exchange markets. In the Pre-B\&R period, the degree of dependence between MYR and SGD was the highest, followed by those between MYR and PHP and between MYR and THB. In the Post-B\&R period, the dependence degree between MYR and SGD was still the highest, whereas the degree of dependence between MYR and IDR jumped to the second-highest, and the correlation of the MYR-PHP pair decreased obviously. Furthermore, it was observed that in the second tree, the values of Kendall's tau in the Post-B\&R period were lower than those in the Pre-B\&R period. Since the Kendall's tau coefficients in the second tree reflect the conditional dependence between currencies of ASEAN countries given the returns of CNY, the lower values of Kendall's tau in the Post-B\&R period give further signals of the increasing power of CNY in the regional foreign exchange markets after the B\&R Initiative was launched.

With regard to the dependence structure, in the Pre-B\&R period, the pair-copula families in the second tree included Frank, Gaussian, Survival BB8, and Joe. The Joe copula had upper tail dependence, which suggests that the correlations of MYR and VND tend to be higher when the two currencies appreciate. However, the copula family of the same exchange rate pair, MYR and VND, changed to be Clayton with lower tail dependence in the Post-B\&R period. Asymmetric dependence of MYR and VND appeared in both periods; this may be another source of systematic risk in the regional foreign exchange markets.

\subsubsection{Brief Summary}

The main findings from the static C-vine analysis are summarized below.

First, the currency returns of the ASEAN countries were positively correlated with the returns of CNY in both periods, except for VND in the Pre-B\&R period, and the correlations were intensified after the B\&R Initiative.

Second, the returns of MYR were highly correlated with the other five ASEAN currencies given the returns of $\mathrm{CNY}$, providing evidence for the possibility of exchange rate co-movements in the foreign exchange markets of China and the ASEAN, also indicating the limited influence of CNY on ASEAN currencies.

Third, the correlations between ASEAN currencies conditional on CNY decreased in the Post-B\&R period compared with in the former period, which implies the increasing power of CNY in ASEAN currency markets.

Fourth, the dependence structure of the exchange rate pairs CNY and IDR, CNY and PHP, and MYR and VND was shown to exhibit lower tail dependence in the Post-B\&R period, which implies asymmetric properties of exchange rate co-movements and a higher degree of dependence during currency depreciation.

\subsection{Estimation Results of the Time-Varying C-Vine Copulas}

In this subsection, the dependence parameters in the C-vine copulas were allowed to change over time. The results from these time-varying C-vine copulas reflect the dynamic characteristics of exchange rate co-movements in the regional currency markets, and help to confirm the robustness of the main findings from the static $\mathrm{C}$-vine copulas.

\subsubsection{Time-Varying Dependence between CNY and the Currencies of Major ASEAN Countries}

The first tree of the time-varying C-vine copulas indicated the dynamic dependence characteristics between CNY and the currencies of ASEAN countries.

The estimated time-varying coefficients for the first tree of the time-varying $\mathrm{C}$-vine copulas are presented in Table 4 . The explanatory factor of the historical correlations is reflected by the coefficients 
$\varphi_{1}$. In the Pre-B\&R period, the coefficients $\varphi_{1}$ were significant for four exchange rate pairs: CNY-MYR, CNY-IDR, CNY-THB, and CNY-VND. This implies that the correlations of the current period were significantly affected by the correlations of the previous period. In the Post-B\&R period, coefficients $\varphi_{1}$ were proved to be significant for exchange rate pairs CNY-MYR, CNY-IDR, CNY-THB, and CNY-PHP. In both periods, all parameters $\varphi_{2}$ were not significant, so no significant variation in the dependence parameter was captured for any exchange rate pair in the first tree.

Table 4. Estimated parameters of the time-varying C-vine copulas (first tree).

\begin{tabular}{cccccc}
\hline Pairs & Time-Varying Copulas & $\varphi_{0}$ & $\varphi_{1}$ & $\varphi_{2}$ & BIC \\
\hline \multicolumn{7}{c}{ Pre-B\&R period (3 August 2009 to 25 December 2013) } \\
\hline CNY-MYR & Time-varying Gaussian & $0.010(0.013)$ & $0.960(0.008)^{* * *}$ & $0.576(0.355)$ & -26.33 \\
CNY-SGD & Time-varying Frank & $0.0191(0.017)^{*}$ & $0.542(0.435)$ & $-0.087(0.084)$ & -20.64 \\
CNY-IDR & Time-varying Frank & $0.054(0.015)^{* * *}$ & $-0.808(0.131)^{* * *}$ & $-0.083(0.056)$ & -16.17 \\
CNY-THB & Time-varying Frank & $0.058(0.022)^{* *}$ & $-0.990(0.035)^{* * *}$ & $0.039(0.033)$ & -15.82 \\
CNY-PHP & Time-varying Gaussian & $0.505(0.222)^{*}$ & $-0.828(0.110)$ & $-1.211(0.759)$ & -6.839 \\
CNY-VND & Time-varying & $-0.222(0.439)$ & $0.943(0.112)^{* * *}$ & $1.244(4.241)$ & 0.121 \\
\hline \multicolumn{7}{c}{ Potated Clayton 90 } \\
Post-B\&R period (1 January 2014 to 25 July 2018) \\
\hline CNY-MYR & Time-varying Gaussian & $1.527(0.243)^{* * *}$ & $-0.917(0.082)^{* * *}$ & $0.943(0.814)$ & -37.42 \\
CNY-SGD & Time-varying Frank & $0.037(0.056)$ & $0.343(0.966)$ & $0.047(0.098)$ & -45.33 \\
CNY-IDR & Time-varying Clayton & $-1.73(0.507)^{* * *}$ & $-0.930(0.098)^{* * *}$ & $1.246(1.23)$ & -33.34 \\
CNY-THB & Time-varying Gaussian & $0.005(0.036)$ & $0.990(0.075)^{* * *}$ & $0.199(0.824)$ & -35.66 \\
CNY-PHP & Time-varying Clayton & $-0.206(0.494)$ & $0.818(0.408)^{*}$ & $-0.753(1.901)$ & -16.09 \\
CNY-VND & Time-varying Gaussian & $0.306(0.220)$ & $0.299(0.483)$ & $-1.125(1.353)$ & -7.85 \\
\hline
\end{tabular}

Note: Significance at the $0.01,0.05$, and 0.10 levels indicated by ${ }^{* * *}, * *$, and ${ }^{*}$; Standard errors in parentheses.

The values of the estimated coefficients of the time-varying C-vine copulas could not reveal the dynamic dependence characteristics intuitively, so we further computed the dynamic Kendall's tau correlations. The time-varying Kendall's tau correlations of the exchange rate pairs in the first tree of the C-vine copulas are summarized in Table 5. The time-varying results also indicated positive dependence between CNY and the currencies of ASEAN countries from the mean and median values. Compared with the Pre-B\&R period, the correlations were intensified obviously in the Post-B\&R period, which confirms the conclusions in the Static analysis.

Table 5. Summary statistics of the time-varying Kendall's tau correlations (first tree).

\begin{tabular}{|c|c|c|c|c|c|c|}
\hline Kendall's Tau & Mean & Median & Max. & Min. & $1^{\text {st }} \mathbf{Q u}$ & $3^{\text {st }} \mathrm{Qu}$ \\
\hline \multicolumn{7}{|c|}{ Pre-B\&R period (3 August 2009 to 25 December 2013) } \\
\hline CNY-MYR & 0.190 & 0.191 & 0.322 & 0.063 & 0.134 & 0.252 \\
\hline CNY-SGD & 0.194 & 0.194 & 0.304 & 0.083 & 0.170 & 0.220 \\
\hline CNY-IDR & 0.151 & 0.158 & 0.371 & -0.075 & 0.107 & 0.198 \\
\hline CNY-THB & 0.157 & 0.160 & 0.288 & 0.002 & 0.129 & 0.187 \\
\hline CNY-PHP & 0.083 & 0.081 & 0.245 & -0.096 & 0.037 & 0.128 \\
\hline CNY-VND & -0.023 & -0.021 & -0.011 & -0.043 & -0.026 & -0.037 \\
\hline \multicolumn{7}{|c|}{ Post-B\&R period (1 January 2014 to 25 July 2018) } \\
\hline CNY-MYR & 0.246 & 0.247 & 0.372 & 0.130 & 0.218 & 0.275 \\
\hline CNY-SGD & 0.297 & 0.295 & 0.340 & 0.248 & 0.284 & 0.308 \\
\hline CNY-IDR & 0.171 & 0.167 & 0.306 & 0.089 & 0.146 & 0.192 \\
\hline CNY-THB & 0.247 & 0.232 & 0.357 & 0.178 & 0.201 & 0.294 \\
\hline CNY-PHP & 0.127 & 0.127 & 0.172 & 0.099 & 0.119 & 0.133 \\
\hline CNY-VND & 0.127 & 0.127 & 0.202 & 0.041 & 0.111 & 0.147 \\
\hline
\end{tabular}


Further, Figure 2 shows plots of the time-varying Kendall's tau correlations from the first tree of the time-varying C-vine copulas before the B\&R Initiative, with the constant Kendall's tau from the static copulas as a reference, while Figure 3 presents the dynamic Kendall's tau correlations after the B\&R Initiative.

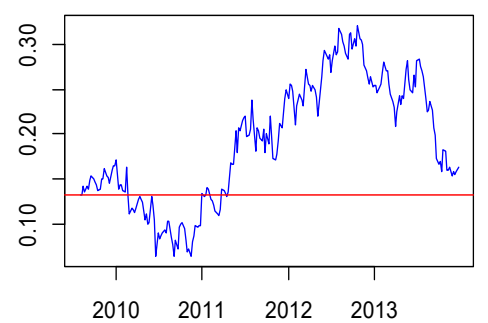

(a) CNY-MYR

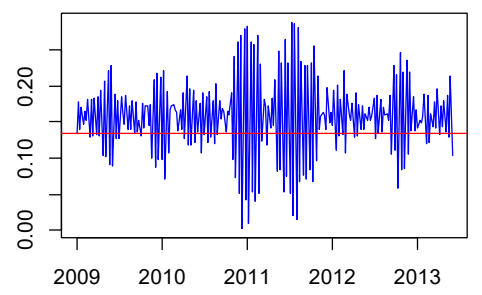

(d) CNY-THB

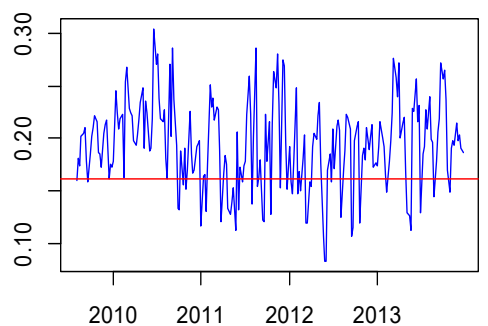

(b) CNY-SGD

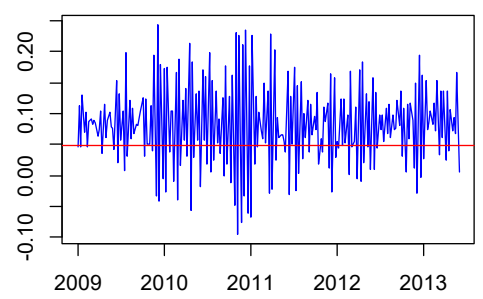

(e) CNY-PHP

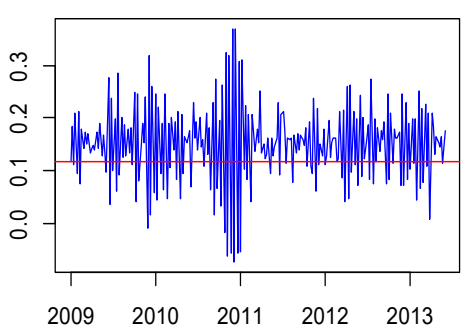

(c) CNY-IDR

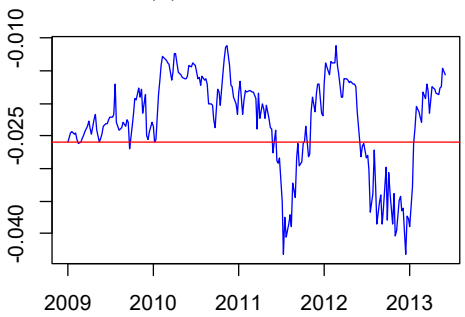

(f) CNY-VND

Figure 2. Kendall's tau correlations from the first tree of the C-vine copulas in the Pre-B\&R period (red lines display the constant Kendall's tau values, while blue lines display the time-varying Kendall's tau values).

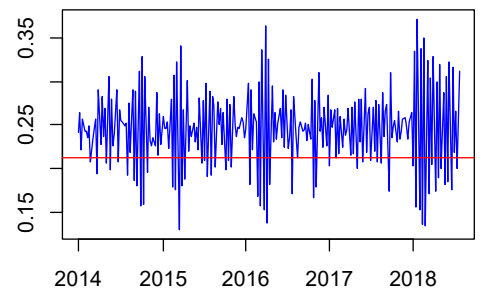

(a) CNY-MYR

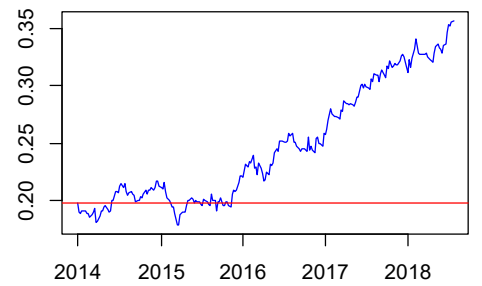

(d) CNY-THB

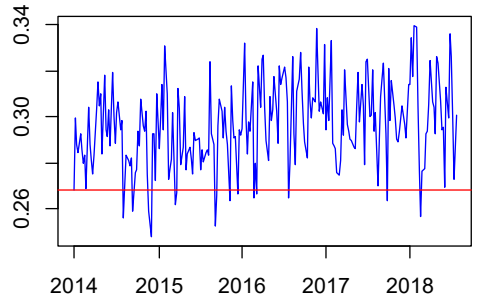

(b) CNY-SGD

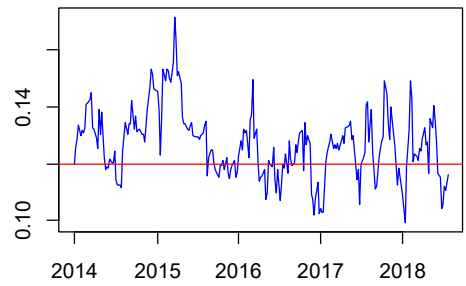

(e) CNY-PHP

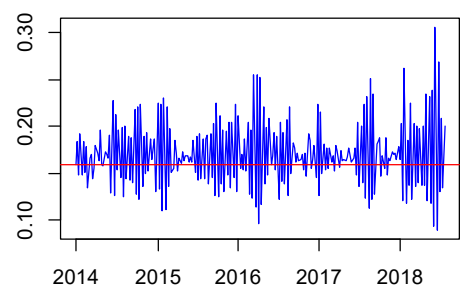

(c) CNY-IDR

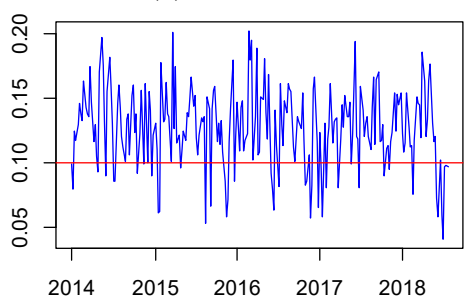

(f) CNY-VND

Figure 3. Kendall's tau from the first tree of the C-vine copulas in the Post-B\&R period (the red lines display the constant Kendall's tau values, while the blue lines display the time-varying Kendall's tau values).

Similar to the findings from the static $\mathrm{C}$-vine copulas, in the Pre-B\&R period, the dynamic correlations of five exchange rate pairs-CNY and MYR, CNY and SGD, CNY and IDR, CNY and $\mathrm{THB}$, and $\mathrm{CNY}$ and $\mathrm{PHP}$ - were almost positive, and fluctuated around their constant correlations as shown in Figure 2. It is noticeable that the dependence between CNY and MYR showed an obvious variation trend. It decreased slowly until mid-2010, then increased obviously until the end of 2012. The increased correlation after the second half of 2010 may be due to the provision of direct quotes between CNY and MYR on the China Foreign Exchange Trade System (CFETS) in August 2010 to facilitate cross-border trade settlement of RMB, reduce conversion costs, and promote bilateral trade 
between China and Malaysia. This event marked the Malaysian Ringgit becoming the first emerging market currency traded in China's interbank market [43]. The direct quotes between CNY and MYR reduced the dependence on U.S. Dollars, deepening cooperation in trade and investment between China and Malaysia. Thus, the correlation between CNY and MYR showed an upward trend.

In the Post-B\&R period, the time-varying Kendall's tau correlations were all positive for the six exchange rate pairs, as shown in Figure 3. The dynamic correlation between CNY and SGD showed a slightly increasing trend after the B\&R Initiative, whereas the dependence between CNY and PHP showed a slight downward trend. Moreover, the dynamic correlations of CNY and THB increased obviously and continuously from 2015, after a Renminbi-Thai Baht bilateral swap agreement (BSA) and a memorandum of understanding (MoU) to establish the Renminbi Clearing Arrangements in Thailand was signed by the People's Bank of China (PBC) and the Bank of Thailand (BOT) at the end of 2014. This currency swap agreement and the establishment of the Renminbi Clearing Arrangements helped Thailand facilitate access to the Chinese onshore foreign exchange market, reducing the costs and enhancing the efficiency of cross-border transactions between China and Thailand. Moreover, the agreements inevitably promoted trade and investment cooperation between China and Thailand. Therefore, the dependence between CNY and THB increased due to deepening cooperation and more convenient trade settlement.

\subsubsection{Dynamic Dependence between the Currencies of Major ASEAN Countries Conditional on CNY}

The second tree of the time-varying C-vine copulas reflected the dynamic dependence characteristics between MYR and the currencies of the other five examined ASEAN countries given CNY. Table 6 shows the estimated time-varying coefficients in the second tree of the C-vine copulas.

The results in Table 6 show that in the Pre-B\&R period, the coefficients $\varphi_{1}$ were significant and positive for all five exchange rate pairs in the second tree of the $\mathrm{C}$-vine copulas, which implies that the current correlations of MYR and SGD, MYR and IDR, MYR and THB, MYR and PHP, and MYR and VND given CNY are all significantly affected by their correlations in the previous period. In the Post-B\&R period, the coefficients $\varphi_{1}$ were significant and positive for only the MYR-SGD and MYR-THB pairs. The coefficients $\varphi_{2}$ were not significant for most of the exchange rate pairs in both periods.

Table 6. Estimated parameters of the time-varying C-vine copulas (second tree).

\begin{tabular}{|c|c|c|c|c|c|}
\hline Pairs & Copulas & $\varphi_{0}\left(\varphi_{3}\right)$ & $\varphi_{1}\left(\varphi_{4}\right)$ & $\varphi_{2}\left(\varphi_{6}\right)$ & BIC \\
\hline \multicolumn{6}{|c|}{ Pre-B\&R period (3 August 2009 to 25 December 2013) } \\
\hline MYR-SGD|CNY & Time-varying Frank & $0.018(0.018)$ & $0.891(0.118)^{* * *}$ & $-0.083(0.089)$ & -154.2 \\
\hline MYR-IDR|CNY & Time-varying Gaussian & $-0.001(0.021)$ & $0.974(0.024)^{* * *}$ & $0.753(0.427)$ & -103.4 \\
\hline MYR-THB|CNY & Time-varying Survival BB8 & $-0.032(0.118)$ & $0.868(0.054)^{* * *}$ & $2.430(1.670)$ & -108.0 \\
\hline MYR-PHP|CNY & Time-varying Gaussian & $\begin{array}{l}0.188(0.220) \\
0.177(0.236)\end{array}$ & $\begin{array}{l}0.956(0.044)^{* * *} \\
0.865(0.152)^{* * *}\end{array}$ & $\begin{array}{r}-1.920(2.647) \\
1.174(1.007)\end{array}$ & $\begin{array}{l}-108.0 \\
-153.8\end{array}$ \\
\hline MYR-VND|CNY & Time-varying Joe & $0.012(0.044)$ & $0.990(0.033)^{* * *}$ & $-4.741(1.588)^{* *}$ & -12.79 \\
\hline \multicolumn{6}{|c|}{ Post-B\&R period (1 January 2014 to 25 July 2018) } \\
\hline MYR-SGD|CNY & Time-varying Gaussian & $0.082(0.048)$ & $0.976(0.020)^{* * *}$ & $-0.886(0.474)$ & -112.8 \\
\hline MYR-IDR|CNY & Time-varying Frank & $0.128(0.053)$ * & $-0.628(0.609)$ & $0.038(0.090)$ & -81.38 \\
\hline MYR-THB|CNY & Time-varying Gaussian & $0.034(0.044)$ & $0.989(0.031)^{* * *}$ & $-0.554(0.496)$ & -55.51 \\
\hline MYR-PHP|CNY & Time-varying Frank & $0.046(0.053)$ & $0.147(0.983)$ & $-0.037(0.102)$ & -37.63 \\
\hline MYR-VND|CNY & Time-varying Clayton & $-3.256(1.036) * *$ & $-0.950(0.038)^{* * *}$ & $3.335(1.878)$ & -9.87 \\
\hline
\end{tabular}

We further looked into the dynamic Kendall's tau correlations in the second tree of the C-vine copulas for both the Pre-B\&R and Post-B\&R periods; the summary statistics of the time-varying Kendall's tau correlations are shown in Table 7. The results were consistent with the previous findings from the static C-vine copulas, which showed that MYR is highly correlated with the other examined 
ASEAN currencies given CNY, and the correlations between the ASEAN currencies conditional on CNY decreased in the Post-B\&R period.

Table 7. Summary statistics of the time-varying Kendall's tau correlations (second tree).

\begin{tabular}{|c|c|c|c|c|c|c|}
\hline & Mean & Median & Max. & Min. & 1st $Q \mathbf{u}$ & 3st Qu \\
\hline \multicolumn{7}{|c|}{ Pre-B\&R period (3 August 2009 to 25 December 2013) } \\
\hline MYR-SGD|CNY & 0.523 & 0.525 & 0.571 & 0.432 & 0.501 & 0.547 \\
\hline MYR-IDR|CNY & 0.392 & 0.385 & 0.597 & 0.228 & 0.310 & 0.460 \\
\hline MYR-THB|CNY & 0.412 & 0.405 & 0.657 & 0.183 & 0.356 & 0.457 \\
\hline MYR-PHP|CNY & 0.497 & 0.502 & 0.580 & 0.355 & 0.468 & 0.527 \\
\hline MYR-VND|CNY & 0.118 & 0.096 & 0.438 & 0.002 & 0.049 & 0.165 \\
\hline \multicolumn{7}{|c|}{ Post-B\&R period (1 January 2014 to 25 July 2018) } \\
\hline MYR-SGD|CNY & 0.428 & 0.429 & 0.543 & 0.246 & 0.391 & 0.476 \\
\hline MYR-IDR|CNY & 0.381 & 0.380 & 0.417 & 0.343 & 0.372 & 0.389 \\
\hline MYR-THB|CNY & 0.317 & 0.314 & 0.414 & 0.194 & 0.279 & 0.348 \\
\hline MYR-PHP|CNY & 0.271 & 0.273 & 0.304 & 0.237 & 0.264 & 0.279 \\
\hline MYR-VND|CNY & 0.097 & 0.084 & 0.492 & 0.011 & 0.065 & 0.492 \\
\hline
\end{tabular}

The time-varying Kendall's tau correlations in the second tree of the C-vine copulas are plotted in Figure 4 (Pre-B\&R period) and Figure 5 (Post-B\&R period). The dynamic correlations between MYR and the other five currencies of ASEAN countries were all positive and fluctuated around the constant Kendall's tau correlations from the static C-vine copulas in both periods.

In the Pre-B\&R period, the correlations of MYR and IDR given CNY showed a noteworthy decreasing trend from 2010 to 2013, as shown in Figure 4. Similarly, the correlations between MYR and VND conditional on CNY also showed a downward trend after 2010. In addition, although the time-varying correlations of MYR and SGD, MYR and THB, and MYR and PHP all fluctuated in the Pre-B\&R period, decreasing trends could also be observed from 2010 to 2011. This decreasing conditional dependence between ASEAN currencies may be due to the increasing influence of CNY on the ASEAN currency markets during this period. This can be explained in two ways. On one hand, the CAFTA established in 2010 contributed to the elimination of import and export tariffs between China and the ASEAN. This cooperation is regarded as an important start of RMB internationalization, and it enlarged the influence of RMB in ASEAN currency markets. On the other hand, bilateral trade growth has been accelerating between China and the ASEAN since 2010. According to the statistics of General Administration of Customs of China (GACC), the total trade volume between China and ASEAN increased by $37.5 \%$ in 2010. The closer trade relation between China and the ASEAN is another motivating factor causing the RMB to become more strongly correlated with ASEAN currencies.

In the Post-B\&R period, as shown in Figure 5, the time-varying Kendall's tau correlations of MYR and SGD given CNY showed a decreasing trend from 2014 to the start of 2015, and showed an increasing trend after that. The time-varying correlations of MYR and THB given CNY increased obviously after 2016, while the correlations of MYR and PHP also showed a slight upward trend after 2015. These findings indicate an increasing trend of correlations between the currencies of ASEAN countries during the Post-B\&R period. ASEAN integration has accelerated since the establishment of the ASEAN Economic Community (AEC) in 2015, which promoted financial and economic integration in the region. The improving integration of ASEAN financial markets could be the reason for the increasing linkages between ASEAN currencies after 2015. The result is consistent with the conclusion by Caporale et al. [14], who found that the ASEAN currencies are much more interlinked than previously thought. The upward trend of these correlations should encourage investors and policy-makers to be cautious about the systematic risks from exchange rate co-movements in the regional currency markets, especially when there is downward pressure on exchange rates. 


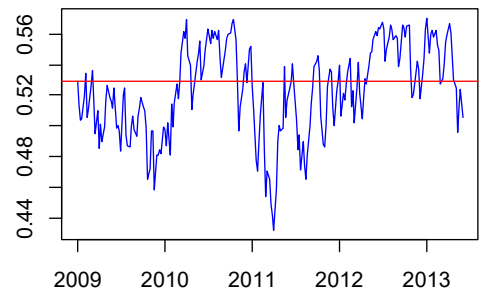

(a) MYR-SGDICNY

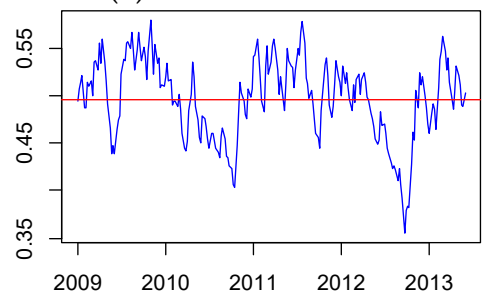

(d) MYR-PHPICNY

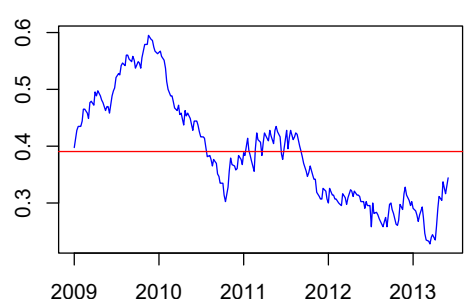

(b) MYR-IDRICNY

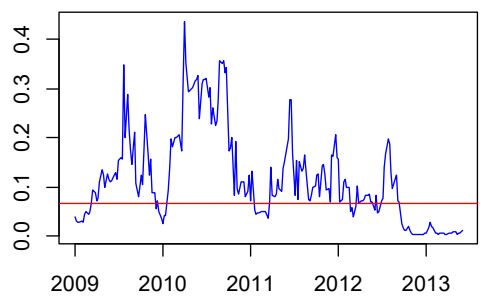

(e) MYR-VNDICNY

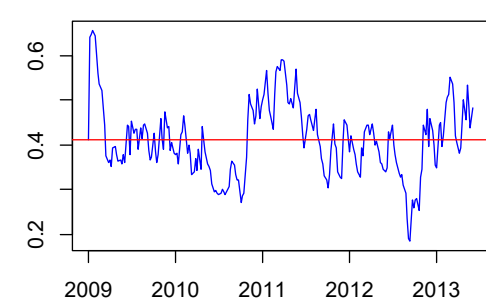

(c) MYR-THB ICNY

Figure 4. Kendall's tau from the second tree of the C-vine copulas in the Pre-B\&R period (red lines display the constant Kendall's tau values, while blue lines display the time-varying Kendall's tau values).

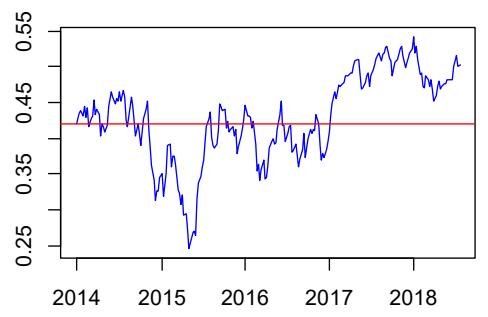

(a) MYR-SGDICNY

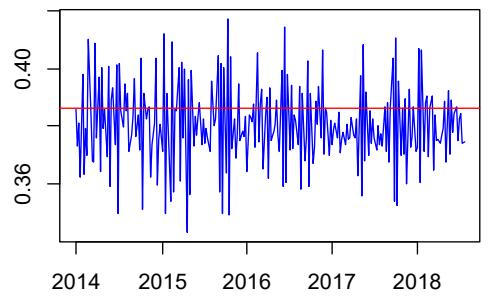

(b) MYR-IDRICNY

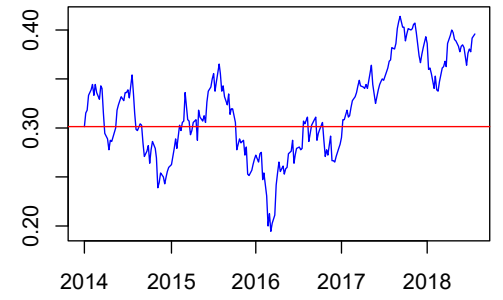

(c) MYR-THB ICNY

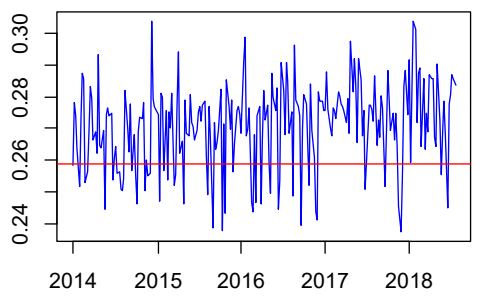

(d) MYR-PHPICNY

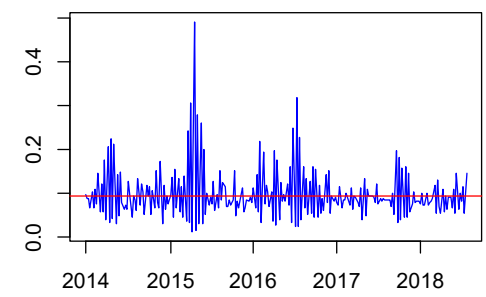

(e) MYR-VNDICNY

Figure 5. Kendall's tau from the second tree of the C-vine copulas in the Post-B\&R period (red lines display the constant Kendall's tau values, while blue lines display the time-varying Kendall's tau values).

\subsubsection{Brief Summary}

The findings from the time-varying C-vine copulas confirmed the robustness of the conclusions from static analysis. The time-varying analysis also revealed positive correlations between the exchange rate of $\mathrm{CNY}$ and the currencies of ASEAN countries, as well as intensified correlations between CNY and ASEAN currencies after the B\&R Initiative. Besides this, it also indicated positive correlations between the currencies of ASEAN countries and the increasing power of CNY in ASEAN foreign exchange markets after the B\&R Initiative.

The plots of the time-varying Kendall's tau values further presented the changing characteristics of dependence between currencies before and after the B\&R Initiative, which could not be reflected in the static analysis. Identifying the dynamic characteristics of dependence in regional currency markets is helpful for investors and policy-makers to make accurate predictions about exchange rate returns when a global shock or a country-specific shock on exchange rates occurs. 


\section{Conclusions}

Given the increasing opportunities for financial cooperation between China and the ASEAN, recognizing the interdependence among exchange rates is crucial for both parties in order to avoid potential systematic risks in the regional currency markets and to stabilize domestic financial markets. In this paper, we investigated the interdependence between the currencies of China and major ASEAN countries using both static and time-varying C-vine copulas, and tried to identify the changing characteristics of dependence after the beginning of the Belt and Road Initiative.

Our findings first indicated positive but limited dependence between the exchange rate returns of CNY and the currencies of ASEAN countries in both periods. As the ASEAN is a highly integrated and cohesive economy, even though the trade and investment linkages between China and the ASEAN have become much stronger and RMB settlement has become more convenient in the regional markets, the correlation between the RMB and ASEAN currencies is still lower compared with the correlation between the ASEAN currencies themselves. Second, the power of the RMB's influence on ASEAN foreign exchange markets increased after the $B \& R$ Initiative was launched. The currency markets of China and ASEAN countries became increasingly integrated because of the continued growing economic and trade relations between China and the ASEAN, as well as the accelerating process of RMB internationalization. Moreover, the obvious change in the correlation between CNY and ASEAN currencies may also be due to the influence of the B\&R Initiative, which contributed to deeper interaction into regional foreign exchange markets through its target of unimpeded trade and financial integration with participating countries. Third, the Malaysian Ringgit was most relevant to the other examined ASEAN currencies, so the MYR exchange rate could play an important role in the stability of regional foreign exchange markets. Moreover, Malaysia is the second-largest trade partner of China among the ASEAN countries, after Vietnam. Therefore, special attention should be paid for to the stability of Malaysia's financial markets in order to avoid the potential systematic risks caused by these strong correlations. Fourth, tail dependence existed in the returns of three currency pairs in the Post-B\&R period: CNY and IDR, CNY and PHP, and MYR and VND. This implies the possibility of the co-movements between these exchange rates being higher during large depreciation of these currencies. Asymmetric dependence structures in financial markets are a non-negligible cause of possible financial and currency crises; thus, systematic risk in the foreign exchange markets of China and the ASEAN caused by asymmetric dependence is also a point of concern. Finally, the results from time-varying C-vine copulas confirmed the robustness of the results of the static $\mathrm{C}$-vine copulas and showed significant dynamic dependence characteristics among the exchange rates in both periods.

Our conclusions confirm the related findings in previous studies, but give a clearer map of the integration of the foreign exchange markets between China and the ASEAN and provide evidence for the rise of the RMB in ASEAN currency markets after the B\&R Initiative. These results may be useful references for policy-makers and investors to adopt proper policies, avoid systematic risks in regional currency markets, ensure the stability of the financial environment, and contribute to further cooperation between China and ASEAN countries under the B\&R Initiative. However, this study also has its limitations. First, we empirically investigated the interdependence and its changing characteristics between the Chinese Yuan and ASEAN currencies, but we did not determine the main influencing factors of the interdependence through quantitative analysis. An extension of this empirical analysis to find the determinants of the dependence between the foreign exchange markets of China and ASEAN may be considered as a future research direction. Second, a comparison between the roles of the Chinese Yuan and the major anchor currency in the ASEAN (U.S. Dollars) could provide a clearer map of the process of RMB internationalization in regional financial markets; this may be another direction for our future study.

Author Contributions: Conceptualization, J.L., M.W., and S.S.; methodology, J.L.; software, J.L. and M.W.; data curation, M.W.; writing—original draft preparation, M.W.; writing—review and editing, J.L., M.W., and S.S.; supervision, J.L. and S.S. 
Funding: This research received no external funding.

Conflicts of Interest: The authors declare no conflict of interest.

\section{References}

1. Lu, X.; Li, J.; Zhou, Y.; Qian, Y. Cross-correlations between RMB exchange rate and international commodity markets. Phys. A Stat. Mech. Appl. 2017, 486, 168-182. [CrossRef]

2. Li, W.; Lu, X.; Ren, Y.; Zhou, Y. Dynamic relationship between RMB exchange rate index and stock market liquidity: A new perspective based on MF-DCCA. Phys. A Stat. Mech. Appl. 2018, 508, 726-739. [CrossRef]

3. Ma, Y.; Wang, J. Co-movement between oil, gas, coal, and iron ore prices, the Australian dollar, and the Chinese RMB exchange rates: A copula approach. Resour. Policy 2019, 63, 101471. [CrossRef]

4. Kwack, S.Y.; Ahn, C.Y.; Lee, Y.S.; Yang, D.Y. Consistent estimates of world trade elasticities and an application to the effects of Chinese Yuan (RMB) appreciation. J. Asian Econ. 2007, 18, 314-330. [CrossRef]

5. Chen, P.F.; Zeng, J.H.; Lee, C.C. Renminbi exchange rate assessment and competitors' exports: New perspective. China Econ. Rev. 2018, 50, 187-205. [CrossRef]

6. Wang, G.J.; Xie, C. Cross-correlations between Renminbi and four major currencies in the Renminbi currency basket. Phys. A Stat. Mech. Appl. 2013, 392, 1418-1428. [CrossRef]

7. McCauley, R.N.; Shu, C. Recent renminbi policy and currency co-movements. J. Int. Money Financ. 2019, 95, 444-456. [CrossRef]

8. Du, J. Examining the Inter-relationship between RMB Markets. Procedia Comput. Sci. 2018, 139, 313-320. [CrossRef]

9. Ruan, Q.; Bao, J.; Zhang, M.; Fan, L. The effects of exchange rate regime reform on RMB markets: A new perspective based on MF-DCCA. Phys. A Stat. Mech. Appl. 2019, 522, 122-134. [CrossRef]

10. Sun, L.; Xiang, M.; Marquez, L. Forecasting the volatility of onshore and offshore USD/RMB exchange rates using a multifractal approach. Phys. A Stat. Mech. Appl. 2019, 532, 121787. [CrossRef]

11. McAleer, M.; Nam, J.C.W. Testing for contagion in ASEAN exchange rates. Math. Comput. Simul. 2005, 68, 517-525. [CrossRef]

12. Muniandy, S.V.; Uning, R. Characterization of exchange rate regimes based on scaling and correlation properties of volatility for ASEAN-5 countries. Phys. A Stat. Mech. Appl. 2006, 371, 585-598. [CrossRef]

13. Sehgal, S.; Pandey, P.; Diesting, F. Examining dynamic currency linkages amongst South Asian economies: An empirical study. Res. Int. Bus. Financ. 2017, 42, 173-190. [CrossRef]

14. Caporale, G.M.; Gil-Alana, L.A.; You, K. Exchange rate linkages between the ASEAN currencies, the US dollar and the Chinese RMB. Res. Int. Bus. Financ. 2018, 44, 227-238. [CrossRef]

15. Jiang, Y.; Yu, M.; Hashmi, S.M. The Financial Crisis and Co-Movement of Global Stock Markets-A Case of Six Major Economies. Sustainability 2017, 9, 260. [CrossRef]

16. Sari, R.; Hammoudeh, S.; Soytaş, U. Dynamics of oil price, precious metal prices, and exchange rate. Energy Econ. 2010, 32, 351-362. [CrossRef]

17. Antonakakis, N. Exchange return co-movements and volatility spillovers before and after the introduction of euro. J. Int. Financ. Mark. Inst. Money 2012, 22, 1091-1109. [CrossRef]

18. Tamakoshi, G.; Hamori, S. Co-movements among major European exchange rates: A multivariate time-varying asymmetric approach. Int. Rev. Econ. Financ. 2014, 31, 105-113. [CrossRef]

19. Dimitriou, D.; Kenourgios, D. Financial crises and dynamic linkages among international currencies. J. Int. Financ. Mark. Inst. Money 2013, 26, 319-332. [CrossRef]

20. Hu, J.W.S.; Chen, M.Y.; Fok, R.C.; Huang, B.N. Causality in volatility and volatility spillover effects between US, Japan and four equity markets in the South China Growth Triangular. J. Int. Financ. Mark. Inst. Money 1997, 7, 351-367. [CrossRef]

21. Wu, C.C.; Chung, H.; Chang, Y.H. The economic value of co-movement between oil price and exchange rate using copula-based GARCH models. Energy Econ. 2012, 34, 270-282. [CrossRef]

22. Sriboonchitta, S.; Nguyen, H.T.; Wiboonpongse, A.; Liu, J. Modeling volatility and dependency of agricultural price and production indices of Thailand: Static versus time-varying copulas. Int. J. Approx. Reason. 2013, 54, 793-808. [CrossRef] 
23. Boero, G.; Silvapulle, P.; Tursunalieva, A. Modelling the bivariate dependence structure of exchange rates before and after the introduction of the euro: A semi-parametric approach. Int. J. Financ. Econ. 2011, 16, 357-374. [CrossRef]

24. Wei, Z.; Wang, T.; Nguyen, P.A. Multivariate dependence concepts through copulas. Int. J. Approx. Reason. 2015, 65, 24-33. [CrossRef]

25. Albulescu, C.T.; Aubin, C.; Goyeau, D.; Tiwari, A.K. Extreme co-movements and dependencies among major international exchange rates: A copula approach. Q. Rev. Econ. Financ. 2018, 69, 56-69. [CrossRef]

26. Benlagha, N. Dependence structure between nominal and index-linked bond returns: A bivariate copula and DCC-GARCH approach. Appl. Econ. 2014, 46, 3849-3860. [CrossRef]

27. So, M.K.; Yeung, C.Y. Vine-copula GARCH model with dynamic conditional dependence. Comput. Stat. Data Anal. 2014, 76, 655-671. [CrossRef]

28. Nikoloulopoulos, A.K.; Joe, H.; Li, H. Vine copulas with asymmetric tail dependence and applications to financial return data. Comput. Stat. Data Anal. 2012, 56, 3659-3673. [CrossRef]

29. Min, A.; Czado, C. SCOMDY models based on pair-copula constructions with application to exchange rates. Comput. Stat. Data Anal. 2014, 76, 523-535. [CrossRef]

30. Tachibana, M. Relationship between stock and currency markets conditional on the US stock returns: A vine copula approach. J. Multinatl. Financ. Manag. 2018, 46, 75-106. [CrossRef]

31. Song, Q.; Liu, J.; Sriboonchitta, S. Risk Measurement of Stock Markets in BRICS, G7, and G20: Vine Copulas versus Factor Copulas. Mathematics 2019, 7, 274. [CrossRef]

32. Ma, Z.; Tian, W.; Li, B.; Wang, T. The Decomposition of Quadratic Forms under Skew Normal Settings. In Proceedings of the International Conference of the Thailand Econometrics Society (TES 2018), Chiang Mai, Thailand, 10-12 January 2018; pp. 222-232.

33. Joe, H. Asymptotic efficiency of the two-stage estimation method for copula-based models. J. Multivar. Anal. 2005, 94, 401-419. [CrossRef]

34. Bedford, T.; Cooke, R.M. Probability Density Decomposition for Conditionally Dependent Random Variables Modeled by Vines. Ann. Math. Artif. Intell. 2001, 32, 245-268. [CrossRef]

35. Aas, K.; Czado, C.; Frigessi, A.; Bakken, H. Pair-copula constructions of multiple dependence. Insur. Math. Econ. 2009, 44, 182-198. [CrossRef]

36. Brechmann, E.C. Czado, Claudia Risk management with high-dimensional vine copulas: An analysis of the Euro Stoxx 50. Stat. Risk Model. 2013, 30, 307-342. [CrossRef]

37. Wei, Z.; Kim, S.; Choi, B.; Kim, D. Multivariate Skew Normal Copula for Asymmetric Dependence: Estimation and Application. Int. J. Inf. Technol. Decis. Mak. 2019, 18, 365-387. [CrossRef]

38. Tian, W.; Wang, C.; Wu, M.; Wang, T. The Multivariate Extended Skew Normal Distribution and its Quadratic Forms. In Causal Inference in Econometrics; Springer: Berlin/Heidelberg, Germany, 2016; pp. 153-169.

39. De Almeida, D.; Hotta, L.K. The leverage effect and the asymmetry of the error distribution in garch-based models: The case of brazilian market related series. Pesqui. Oper. 2014, 34, 237-250. [CrossRef]

40. Ma, X.; Yang, R.; Zou, D.; Liu, R. Measuring extreme risk of sustainable financial system using GJR-GARCH model trading data-based. Int. J. Inf. Manag. 2019, in press. [CrossRef]

41. Zhang, L.; Cui, L.; Li, S.; Lu, J. Who rides the tide of regionalization: Examining the effect of the China-ASEAN Free Trade Area on the exports of Chinese firms. Int. Bus. Rev. 2018, 27, 501-513. [CrossRef]

42. Bloomberg News. Available online: https://www.bloomberg.com/news/articles/2019-02-27/tradetruce-maythrow-up-a-surprise-winner-the-singapore-dollar (accessed on 27 February 2019).

43. Lee, I.H.; Park, Y.C. Use of National Currencies for Trade Settlement in East Asia: A Proposal. In Financial Development and Cooperation in Asia and the Pacific; Routledge: Abingdon, UK, 2014; pp. 204-230.

(C) 2019 by the authors. Licensee MDPI, Basel, Switzerland. This article is an open access article distributed under the terms and conditions of the Creative Commons Attribution (CC BY) license (http://creativecommons.org/licenses/by/4.0/). 